\title{
BMJ Open Factors associated with non-beneficial treatments in end of life hospital admissions: a multicentre retrospective cohort study in Australia
}

\author{
Hannah Elizabeth Carter (10 , ${ }^{1}$ Xing Ju Lee (D) , ${ }^{1}$ Cindy Gallois, ${ }^{2}$ Sarah Winch, ${ }^{3}$ \\ Leonie Callaway (1) ,,$^{3,4}$ Lindy Willmott (D), ${ }^{5}$ Ben White (D), ${ }^{5}$ Malcolm Parker (D) , \\ Eliana Close (D) , ${ }^{5}$ Nicholas Graves (D) ${ }^{1,6}$
}

To cite: Carter HE, Lee XJ, Gallois $\mathrm{C}$, et al. Factors associated with non-beneficial treatments in end of life hospital admissions: a multicentre retrospective cohort study in Australia. BMJ Open 2019;9:e030955. doi:10.1136/ bmjopen-2019-030955

- Prepublication history and additional material for this paper are available online. To view these files, please visit the journal online (http://dx.doi. org/10.1136/bmjopen-2019030955).

Received 09 April 2019 Revised 02 October 2019 Accepted 04 October 2019

Check for updates

(C) Author(s) (or their employer(s)) 2019. Re-use permitted under CC BY-NC. No commercial re-use. See rights and permissions. Published by BMJ.

For numbered affiliations see end of article.

Correspondence to Dr Hannah Elizabeth Carter; hannah.carter@qut.edu.au

\section{ABSTRACT}

Objective To quantitatively assess the factors associated with non-beneficial treatments (NBTs) in hospital admissions at the end of life.

Design Retrospective multicentre cohort study.

Setting Three large, metropolitan tertiary hospitals in Australia.

Participants 831 adult patients who died as inpatients following admission to the study hospitals over a 6-month period in 2012.

Main outcome measures $0 \mathrm{dds}$ ratios (ORs) of NBT derived from logistic regression models.

Results Overall, 103 (12.4\%) admissions involved NBTs. Admissions that involved conflict within a patient's family (OR 8.9, 95\% $\mathrm{Cl} 4.1$ to 18.9 ) or conflict within the medical team (OR 6.5, 95\% $\mathrm{Cl} 2.4$ to 17.8) had the strongest associations with NBTs in the all subsets regression model. A positive association was observed in older patients, with each 10-year increment in age increasing the likelihood of NBT by approximately $50 \%$ (OR 1.5, $95 \% \mathrm{Cl} 1.2$ to 1.9 ). There was also a statistically significant hospital effect.

Conclusions This paper presents the first statistical modelling results to assess the factors associated with NBT in hospital, beyond an intensive care setting. Our findings highlight potential areas for intervention to reduce the likelihood of NBTs.

\section{INTRODUCTION}

The provision of non-beneficial treatment (NBT) in hospital admissions at the end of life is ineffective, ${ }^{1}$ costly $^{2-4}$ and causes unnecessary distress to patients, families and medical staff. ${ }^{56}$ NBT describes treatments that have only a very low chance of achieving meaningful benefit for the patient in terms of: improving quality of life; sufficiently prolonging life of acceptable quality; or bringing benefits that outweigh the burdens of treatment. ${ }^{7}$ These types of treatments have also been referred to as 'futile' or 'potentially inappropriate', 8 and more recently have been identified as part of a broader phenomenon termed 'treatment overuse'. ${ }^{9}$ A
Strengths and limitations of this study

- This is the first study to apply statistical modelling techniques to assess the factors associated with non-beneficial treatment (NBT) in hospital, beyond the intensive care setting.

- Our data-based approach enabled the objective assessment of various patient and hospital related factors and allowed for the use of statistical tests to inform the generalisability of our results to the population.

- By analysing data from three major hospitals we were able to examine factors that may influence NBT at the organisational level.

- A limitation of our study design was the retrospective nature of the clinical audit that was used to identify whether an admission involved NBT, which may have introduced confirmation bias.

- While the audit adopted a consensus definition of NBT, this is an inherently subjective and valueladen term and its interpretation may differ between individuals.

recent systematic review highlighted the extent of this issue in routine hospital care at the end of life, reporting that an average of 33\%-38\% of patients received NBTs. ${ }^{10}$ In Australia, such treatments have been estimated to cost $\$ \mathrm{~A}$ 153 million to the healthcare system each year. ${ }^{2}$

Understanding the nature of NBT, including reasons why it is given, provides an evidence base to develop interventions to reduce it. A recent study conducted interviews with 96 doctors routinely involved in delivering end of life care and identified a number of interrelated factors that contributed to the provision of NBT. These factors related to (1) the treating doctors; (2) patients or families; (3) the hospital environment. ${ }^{11}$ This and related work lay the foundations for the quantitative study we report here. The application of statistical modelling methods in addressing 
the question of why NBT occurs is a novel approach, with previous studies typically reporting on perceptions of doctors or healthcare providers, and many being limited to the intensive care setting. ${ }^{512-21}$

By applying logistic regression methods to estimate the association of specific factors with NBT in hospital admissions at the end of life, we aimed to provide new evidence for why NBTs are delivered in an acute hospital setting. This may inform efforts to reduce NBT with prospective interventions. We used the Strengthening the Reporting of Observational Studies in Epidemiology checklist as our reporting guide. ${ }^{22}$

\section{METHODS}

\section{Study design, setting and participants}

A retrospective clinical audit was undertaken to identify cases of NBT in adult admissions that ended in death. Admissions were sourced from three tertiary referral hospitals in a metropolitan region of Australia and included all consecutive, eligible admissions over a 6-month period between March and September 2012. Patients aged under 18 years were excluded, as were patients declared dead on arrival, even if they were placed on life support to facilitate organ donation. A total of 907 adult admissions were included in this study. Multicentre ethics approval for the study was obtained for all the relevant hospitals and participating universities. Access to patients' medical records was granted by the state health department.

\section{Patient and public involvement}

Patients and the public were not involved in the design or planning of this study.

\section{Clinical audit}

A multistage audit process was used to inform judgements about whether an admission involved NBTs, which was referred to as 'futile treatment'. This involved an initial nurse audit in which a purpose-developed audit tool was used to identify admissions that had the possibility of futile treatment. A copy of this tool is included in online supplementary file 1. Nurses were asked to classify each admission as involving treatment that was either 'not futile' or 'potentially' futile' along with a score reflecting how confident they were in their classification on a scale of $0 \%-100 \%$. The nurses' judgements were based on this definition:

Futile treatment is treatment which has only a very low chance of achieving a meaningful benefit for the patients in terms of: improving the patient's quality of life; significantly prolonging the patient's life of acceptable quality; or involving burden that outweighs benefit. $^{7}$

Cases where nurses were more than $70 \%$ confident that no futile treatment was provided were screened out at this point. Of 160 admissions that possibly involved futile treatment, one was lost to follow-up and the remaining
159 were subsequently audited in up to three rounds of independent reviews by consultants (senior medical specialists). Consultants were based at the study hospitals, were experienced in end of life care and came from a wide range of specialities.

Consultants' judgements on the presence and timing of futile treatment were made based on the same definition used in the nurse audit. Five consultants initially reviewed each case, with an $80 \%$ consensus required for an admission to be classified as involving futile treatment. Where a consensus could not be reached, an admission went through a second round of independent review with an additional five consultants. A combined minimum consensus of $60 \%$ across both rounds of review was required for a judgement on futile treatment to be made. For the final 30 admissions where consensus had not been reached, a third and final round of review was undertaken using three face-to-face panels of four or five consultants, who discussed each case until a final determination was made. Further details on the clinical audit process have been reported previously. ${ }^{2}$

\section{Data items}

A number of data items were extracted from patient medical records. We selected a subset of these items that were determined to be of potential relevance in predicting or explaining NBTs. We made this selection based on previous research (our own and other published studies) and the judgements of our expert clinical reference group. ${ }^{11} 18$ We selected data on individual patient characteristics included age, sex, non-English-speaking background, smoking and alcohol status, relationship status, exercise tolerance, aged care residency, level of dependency for activities of daily living and number of admissions in the past 3 years.

Data on whether there was evidence of advance care planning prior to the admission was obtained from patient notes. In Australia, Advance Care Planning refers to the process of talking through prognosis, viability of treatment, survivability, substitute decision makers and when comfort measures should start. It can be conducted by a doctor or by nursing staff. The Advance Health Directive is a legal document that reflect the decisions made in the Advanced Care Planning discussions such as refusal of resuscitation or artificial respiration. The Enduring Power of Attorney is a formal document that provides another person the authority to make personal or financial decisions on a patient's behalf. Patients hold these documents and are required to bring them to hospital. Information from these legal documents is then kept in patients' charts and accessible to all medical staff. Hospitals also have an admission initiated Acute Resuscitation Plan that documents whether a patient wishes to be resuscitated during the course of the admission.

Data on the nature and course of the admission included whether a patient had been transferred from another hospital, whether a patient was admitted to the intensive care unit, whether death occurred while in intensive care 
unit (ICU), whether a decision was recorded either not to treat or to withdraw treatment, and the medical specialty the patient was being managed under at the time of death. Responses to the Supportive \& Palliative Care Indicators Tool (SPICT) were also utilised. The SPICT (online supplementary file 2) is a validated tool used to identify patients at risk of deteriorating and dying with one or multiple advanced conditions. It is designed for use in palliative care needs assessment and planning.

It is common for hospital based social workers to be involved in end of life admissions in Australia, and family meetings are typically conducted as part of this process. The presence of conflict involving families was obtained from detailed social work notes. Examples of these types of conflicts included disagreements between family members on the continuation of treatment or the timing of extubation, as well as disagreements between family members and medical staff around treatment cessation or the need for more invasive interventions such as chemotherapy. The presence of conflict within medical teams was obtained from nursing and medical notes and largely related to the changing of orders, not following through with orders or disagreements about the appropriateness of orders.

Data from patient charts describing the cause of death were coded according to the WHO definition of 'underlying cause of death' and assigned Major Diagnostic Category (MDC) as defined in the WHO International Classification of Diseases. ${ }^{23}$ Deaths with multiple identified causes, where the single underlying cause could not be determined, were classified as involving either two, or three and above, MDCs.

\section{Statistical analysis}

A large number of covariates were identified as being potentially informative about the provision of NBT. Logistic regression models were used to quantify the association between the identified covariates and NBT. Odds ratios (ORs) were produced for each covariate, along with $95 \%$ CIs to quantify the uncertainty in the estimates.

First, each covariate was independently tested for its association with NBT in a series of independent univariable logistic regression models as a form of exploratory data analysis. A full multivariable logistic regression model which included all covariates was then fitted to the data. This model was able to estimate the associations with NBT when controlling for effects of other covariates.

Given the number of covariates identified, we then investigated whether it was possible to identify a concise set of covariates to explain the NBT provision observed in the data set. For this, we used 'all possible subsets' regression to determine the combination of covariates that were most strongly associated with NBT. The 'all possible subsets' regression method fits regression models to all possible combinations of the covariates, and ranks each model fitted using an information criterion. ${ }^{24}$ Model inferences can then be made from model averaging estimates from all subsets, or using a selection of most informative models. We used the Bayesian information criterion (BIC) to rank the fitted modes. ${ }^{25}$ This method is robust compared with simple stepwise regression procedures which are more susceptible to selecting a local optimum by construct. The use of BIC also accounts for model selection uncertainty by producing model average estimates instead of relying on estimates from a single fitted model. ${ }^{26-28}$

Relative to the multivariable regression method, the all possible subsets regression can be considered a comparatively more robust approach as it considers all possible covariate configurations for a given full model specification, and selects the fitted model with the optimal criterion value out of all candidate models (formed from the possible covariate configurations). We appreciate that variable selection can be a contentious matter ${ }^{29}$ and have provided results from the full multivariable model, as well as the variable selection results from both all subset and simple stepwise approaches along with additional statistical details in online supplementary file 3 . The different approaches produced broadly consistent results.

\section{RESULTS}

\section{Descriptive statistics}

There were 907 admissions included in the clinical audit, with one record lost to follow-up. An additional 75 admissions were excluded from this analysis due to missing data, including seven that involved NBT. Admissions were excluded if data were missing on sex (four admissions), marital status (33 admissions), carer status (29 admissions), advance care planning (15 admissions) and cause of death (three admissions). There were 62 missing entries in the exercise covariate, so these were grouped into a 'missing' category.

Of the remaining 831 admissions in our sample, 103 $(12.4 \%)$ involved NBT. Table 1 summarises the characteristics of admissions according to the involvement of NBT. An expanded version of this table containing the full variable list is available in online supplementary file 4 . The average length of stay was 11.1 days (SD 17.2 days).

\section{Multivariable associations with NBT}

Table 2 lists the ORs produced by the multivariable regression analysis. An expanded version of this table containing the full variable list is available in online supplementary file 5 . The presence of conflicts involving families had the strongest association with NBT, with these admissions being 10 times more likely to involve NBT (OR 10.52, $95 \%$ CI 4.27 to 26.49). Conflict in the medical team was also a strong predictor of NBT (OR 8.44, 95\% CI 2.56 to 29.23). A post hoc analysis revealed that these two covariates were statistically independent, with only three admissions involving both family and medical conflicts, and one of these involving NBT.

The multivariable regression also revealed that NBT was strongly associated with the presence of Enduring Power of Attorney documents, admission to ICU and very low 
Table 1 Characteristics of the cohort, according to whether admissions involved NBT. Values are numbers (percentage of cohort) unless indicated otherwise

\begin{tabular}{|c|c|c|c|}
\hline Characteristics & $\begin{array}{l}\text { Admissions } \\
\text { without NBT } \\
\text { ( } n=728)\end{array}$ & $\begin{array}{l}\text { Admissions } \\
\text { involving NBT } \\
\text { ( } n=103)\end{array}$ & Total $(n=831)$ \\
\hline \multicolumn{4}{|l|}{ Hospital } \\
\hline A & $301(41 \%)$ & 20 (19\%) & $321(39 \%)$ \\
\hline B & $248(34 \%)$ & $36(35 \%)$ & $284(34 \%)$ \\
\hline $\mathrm{C}$ & $179(25 \%)$ & 47 (46\%) & $226(27 \%)$ \\
\hline \multicolumn{4}{|l|}{ Personal characteristics } \\
\hline Age (mean, SD) & $71.7(16.1)$ & $76.4(17.1)$ & $72.3(18.1)$ \\
\hline Male & $411(56 \%)$ & $53(51 \%)$ & $464(56 \%)$ \\
\hline Non-English-speaking background & $52(7 \%)$ & $12(12 \%)$ & $64(8 \%)$ \\
\hline Married/de facto & $382(52 \%)$ & $50(49 \%)$ & $432(52 \%)$ \\
\hline Alcohol use* & $118(16 \%)$ & $19(18 \%)$ & $137(16 \%)$ \\
\hline Smoker & $89(12 \%)$ & $9(9 \%)$ & $98(12 \%)$ \\
\hline Is a carer & $32(4 \%)$ & $9(9 \%)$ & $41(5 \%)$ \\
\hline Aged care resident & $99(14 \%)$ & $12(12 \%)$ & $111(13 \%)$ \\
\hline \multicolumn{4}{|l|}{ Activities of daily living } \\
\hline Dependent & $111(15 \%)$ & $22(21 \%)$ & $133(16 \%)$ \\
\hline Partially dependent & $287(39 \%)$ & $40(39 \%)$ & 327 (39\%) \\
\hline Independent & $330(45 \%)$ & $41(40 \%)$ & $371(45 \%)$ \\
\hline \multicolumn{4}{|l|}{ Exercise tolerance } \\
\hline No limits & $137(19 \%)$ & $11(11 \%)$ & $148(18 \%)$ \\
\hline Ordinary activities result in fatigue/symptoms & $227(31 \%)$ & $30(29 \%)$ & $257(31 \%)$ \\
\hline Less than ordinary activities result in fatigue/symptoms & $288(40 \%)$ & $50(49 \%)$ & $338(41 \%)$ \\
\hline Bed bound & $42(6 \%)$ & $9(9 \%)$ & $51(6 \%)$ \\
\hline Missing & $34(5 \%)$ & $3(3 \%)$ & $37(4 \%)$ \\
\hline \multicolumn{4}{|l|}{ Previous admissions over the past 3 years } \\
\hline 0 & $202(28 \%)$ & $34(33 \%)$ & $236(28 \%)$ \\
\hline 1 & $124(17 \%)$ & $20(19 \%)$ & $144(17 \%)$ \\
\hline 2 & $95(13 \%)$ & $12(12 \%)$ & $107(13 \%)$ \\
\hline three or more & $307(42 \%)$ & $37(36 \%)$ & $344(41 \%)$ \\
\hline \multicolumn{4}{|l|}{ End of life planning } \\
\hline Advance care planning in place & $239(33 \%)$ & $43(42 \%)$ & $282(34 \%)$ \\
\hline Advance health directive & $56(8 \%)$ & $7(7 \%)$ & $63(8 \%)$ \\
\hline Enduring power of attorney & $186(26 \%)$ & $41(40 \%)$ & $227(27 \%)$ \\
\hline Palliative care review & $34(5 \%)$ & $4(4 \%)$ & $38(5 \%)$ \\
\hline Acute resuscitation plan & $21(3 \%)$ & $5(5 \%)$ & $26(3 \%)$ \\
\hline Not-for-resuscitation order & $17(2 \%)$ & $4(4 \%)$ & $21(3 \%)$ \\
\hline \multicolumn{4}{|l|}{ Admission characteristics } \\
\hline Length of stay (mean, SD) & $9.6(15.7)$ & $21.2(22.8)$ & $11.1(17.2)$ \\
\hline Inter-regional transfer & $174(24 \%)$ & $34(33 \%)$ & 208 (25\%) \\
\hline Admitted to ICU & $181(25 \%)$ & $33(32 \%)$ & $214(26 \%)$ \\
\hline Death in ICU & $145(20 \%)$ & $18(17 \%)$ & $163(20 \%)$ \\
\hline Conflict in medical team & $10(1 \%)$ & $11(11 \%)$ & $21(3 \%)$ \\
\hline Conflict involving family & $20(3 \%)$ & $18(17 \%)$ & $38(5 \%)$ \\
\hline
\end{tabular}




\begin{tabular}{clll}
\hline & $\begin{array}{l}\text { Admissions } \\
\text { without NBT } \\
(\mathbf{n = 7 2 8})\end{array}$ & $\begin{array}{l}\text { Admissions } \\
\text { involving NBT } \\
(\mathbf{n = 1 0 3 )}\end{array}$ & Total (n=831) \\
\hline Decision not to treat or to withdraw treatment & $641(88 \%)$ & $91(88 \%)$ & $732(88 \%)$ \\
\hline
\end{tabular}

*Positive responses refer to any level of alcohol consumption. ICU, intensive care unit; NBT, non-beneficial treatment.

exercise tolerance. NBT was more likely to occur in older patients, but less likely to occur in aged care residents. Relative to hospital A, patients admitted to hospital B had approximately 2.7 times the risk of NBT after controlling for covariates, while patients admitted to hospital C had more than six times the risk.

\section{All subset regression associations with NBT}

The results of the all subset regression approach are presented in figure 1. Family conflict (OR 8.9, 95\% CI 4.1 to 18.9 ) and medical team conflict (OR 6.5, 95\% CI 2.4 to 17.8 ) remained strongly associated with NBT. Older patients were more likely to receive NBT (OR 1.5, 95\% CI 1.2 to 1.9$)$ and there remained a hospital effect on the provision of NBT (OR 2.5, 95\% CI 1.4 to 4.6 for hospital $\mathrm{B}$, and $4.5,95 \% \mathrm{CI} 2.4$ to 8.4 for hospital C).

Additional positive associations were found for ICU admission (OR 1.7, 95\% CI 0.7 to 4.6), the SPICT item for persistent symptoms (OR 1.4, 95\% CI 0.7 to 3.1), and Enduring Power of Attorney (OR 1.3 (95\% CI 0.7 to 2.6); these were not statistically significant at the $95 \%$ level of confidence.

\section{DISCUSSION}

We used logistic regression models to identify the factors associated with NBT in end of life hospital admissions and to quantify the strength of these associations. Conflict within families and medical teams were identified as strong predictors of NBT provision, while patient age and hospital of admission were also significant factors.

The reasons for the associations between the presence of conflict and NBT are unclear. Notably, the presence of conflicts within medical teams $(n=21)$ and those involving families $(n=38)$ were largely independent. Only three admissions were observed as including both. Our finding is consistent with a previous study which showed that greater family discord was associated with stronger preferences for life-prolonging treatments and weaker preferences for palliative care, independently of end of life values and sociodemographic characteristics. ${ }^{30}$ It is possible that conflict is more likely to arise in scenarios where clinical decisions are less straightforward, and the potential for differences in opinion is greater. In such cases, there may be a tendency to err on the side of caution and provide NBT to maintain the status quo until the conflict is resolved. This was identified by some doctors as a factor in the previously reported qualitative component of this study. ${ }^{11}$ Similar reasoning might also explain the higher risk of NBT in older patients, where the complexity of clinical decisions may be greater. The design of our study and the data available did not allow for us to explore the nature of this relationship further, but it should be examined in future studies.

Regardless of the reasons underlying the significance of conflict in NBT at the end of life, these findings suggest there is potential to reduce such treatments through improved conflict management practices. A report commissioned by the New South Wales Department of Health identified that most conflicts within end of life care were initiated by communication breakdown. ${ }^{31}$ The most effective strategies for preventing and managing such conflict are therefore likely to be those that address this aspect of clinical practice. 'Collaborative communication' or 'compassionate communication' approaches may assist, where there is a focus on the feelings of family members and the identification of unmet needs. ${ }^{32-34}$ Other factors the report identities as contributing to conflict in end of life care decisions included disparate expectations, avoidance of end of life discussions, and time constraints. Overall, the report found there is relatively little evidence internationally around 'what works' in preventing or managing end of life conflict.

Age was the only individual patient characteristic to be significantly associated with NBT in both multivariable and 'all possible subsets' regressions. This builds on the findings reported in the development of the Criteria for Screening and Triaging to Appropriate aLternative care (CriSTAL) tool which aims to quantify the risk of death in elderly hospital patients in order to minimise prognostic uncertainty and avoid potentially harmful treatments. ${ }^{10}$ The CrisSTAL tool identifies old age as a priority given the evidence of its strength in predicting death in hospital admissions. Our finding that old age was associated with NBT within a cohort of terminal admissions indicates that the predictive nature of old age in the provision of NBT occurs independently of its ability to predict death.

We have previously published results on the incidence of NBT in this cohort, which ranged from a rate of $6 \%$ in hospital A to $20 \%$ in hospital C. ${ }^{2}$ This paper builds on this evidence by applying hospital as a covariate in a regression model to determine its ability to predict NBT, both independently and while controlling for a large number of patient and hospital specific covariates. Hospital of admission remained a significant predictor across both 


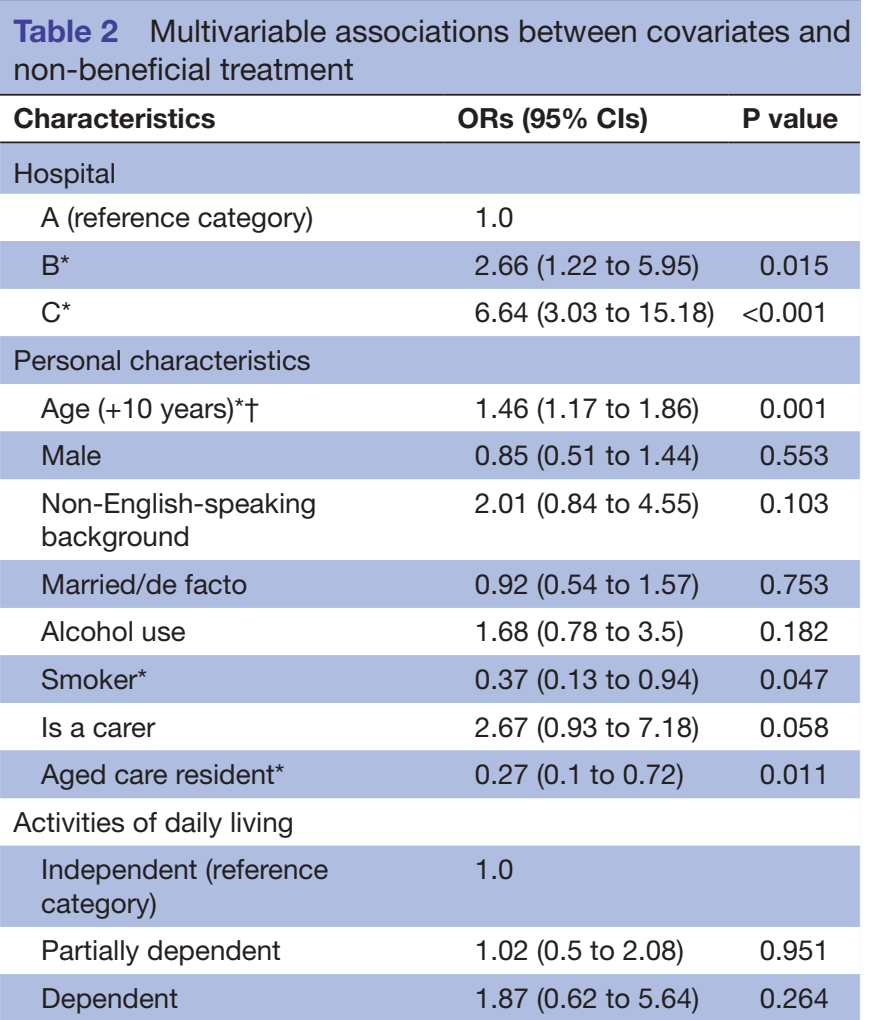

\section{Exercise tolerance}

\begin{tabular}{|c|c|c|}
\hline No limits (reference category) & 1.0 & \\
\hline $\begin{array}{l}\text { Ordinary activities result in } \\
\text { fatigue/symptoms* }\end{array}$ & 2.61 (1.04 to 6.94$)$ & 0.046 \\
\hline $\begin{array}{l}\text { Less than ordinary activities } \\
\text { result in fatigue/symptoms }\end{array}$ & $4.87(1.72$ to 14.71$)$ & 0.003 \\
\hline Bed bound & $3.74(0.79$ to 17.78$)$ & 0.096 \\
\hline Missing & 0.82 (0.16 to 3.42 ) & 0.800 \\
\hline
\end{tabular}

Previous admissions over the past

3 years

\begin{tabular}{|c|c|c|}
\hline 0 (reference category) & 1.0 & \\
\hline 1 & 1.04 (0.49 to 2.19$)$ & 0.917 \\
\hline 2 & $0.54(0.21$ to 1.31$)$ & 0.186 \\
\hline three or more & $0.84(0.41$ to 1.7$)$ & 0.619 \\
\hline \multicolumn{3}{|l|}{ End of life planning } \\
\hline Advance care planning in place & $0.26(0.05$ to 1.12$)$ & 0.084 \\
\hline Advance health directive & $1.3(0.41$ to 3.75$)$ & 0.643 \\
\hline Enduring power of attorney* & 7.73 (1.91 to 38.1$)$ & 0.007 \\
\hline Palliative care review & $0.76(0.11$ to 4.22$)$ & 0.765 \\
\hline Acute resuscitation plan & 0.55 (0.08 to 3.3$)$ & 0.527 \\
\hline Not-for-resuscitation order & 3.05 (0.41 to 20.82$)$ & 0.263 \\
\hline \multicolumn{3}{|l|}{ Admission characteristics } \\
\hline Inter-regional transfer* & 2.12 (1.12 to 4.02$)$ & 0.021 \\
\hline Admitted to ICU* & 5.8 (2.27 to 14.59$)$ & $<0.001$ \\
\hline Death in ICU & $0.4(0.15$ to 1.1$)$ & 0.075 \\
\hline Conflict in medical team* & 8.44 (2.56 to 29.23$)$ & $<0.001$ \\
\hline Conflict involving family* & 10.52 (4.27 to 26.49$)$ & $<0.001$ \\
\hline $\begin{array}{l}\text { Decision not to treat or to } \\
\text { withdraw treatment }\end{array}$ & 0.82 (0.38 to 1.89$)$ & 0.629 \\
\hline
\end{tabular}

Continued
Table 2 Continued

$\begin{array}{lll}\text { Characteristics } & \text { ORs }(95 \% \mathrm{Cls}) \quad \text { P value }\end{array}$

${ }^{*} \mathrm{p}<0.05$.

†Age was modelled in 10-year increments by dividing the age covariate by 10 .

ICU, intensive care unit.

multivariable and all subsets regressions. This strengthens the evidence to suggest that the observed differences in NBT between hospitals may be influenced by cultural or organisational practices and barriers, separate to observed variations in patient demographics or the clinical case-mix. Findings from previous qualitative work in these hospitals identified a number of hospital-specific factors, including a high degree of specialisation, the availability of routine tests and interventions, and organisational barriers to diverting a patient from a curative to a palliative pathway. ${ }^{11}$ A lack of palliative care team consultation has also been identified as a statistically significant predictor of NBT in cancer patients in an intensive care setting. ${ }^{35}$ It is noteworthy that hospital A was the only hospital in our study with a dedicated palliative care ward, although all the hospitals had palliative pathways. Further research is needed to determine the efficacy of specialised palliative care unit on reducing NBT.

An unexpected finding was that most covariates were not associated with NBT. The lack of correlation between NBT and clinical factors including cause of death and medical specialty suggests that this issue is not limited to specific medical fields. This points to the need for systemwide interventions that can be implemented and adapted across a range of clinical settings.

This is the first study to apply statistical modelling techniques to assess the factors associated with NBT beyond

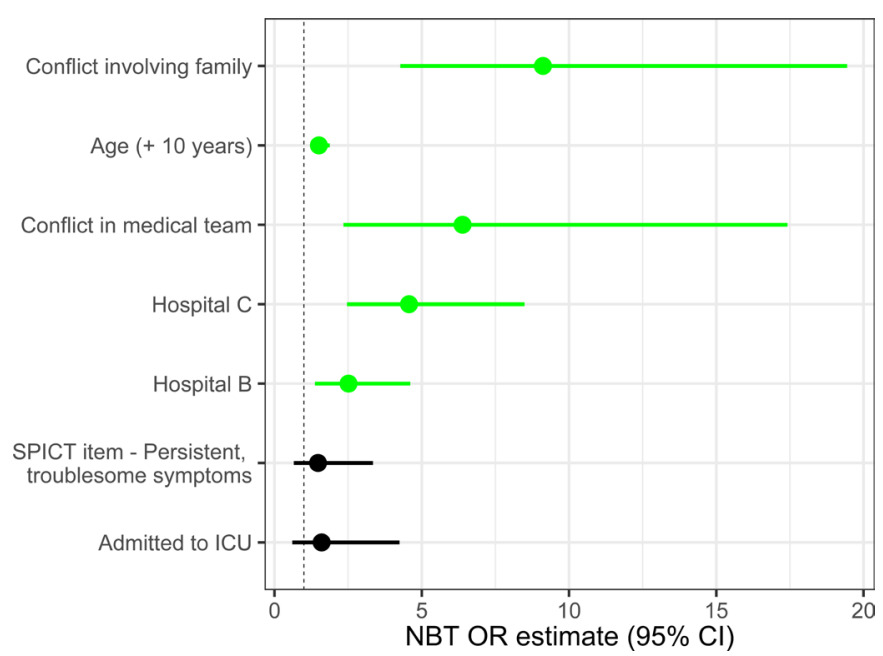

Figure 1 Factors associated with NBT in the final fitted all subset regression logistic model. Point estimates are represented by dots, and $95 \% \mathrm{Cls}$ are shown as bars. Green bars are statistically significant at 0.05 significance level. ICU, intensive care unit; NBT, non-beneficial treatment; SPICT, Supportive \& Palliative Care Indicators Tool. 
the ICU setting. We are aware of just two previous studies that have applied a statistical model to determine the factors associated with NBT; these were both specific to a single site intensive care unit with results that have limited generalisability to the broader hospital setting. ${ }^{35} 36$ We used a dataset containing detailed information on a large number of patient-specific and admission-specific factors. In utilising data from three major hospitals we were also able to examine factors that may influence NBT at the organisational level. Our data-based approach enabled the objective assessment of various patient and hospital related factors and allowed for the use of statistical tests to inform the generalisability of our results to the population.

A key limitation of our study design was the retrospective nature of the clinical audit that was used to identify whether an admission involved NBT, which may have introduced confirmation bias. The decision to identify an admission as involving NBT was also based on the perceptions of nurses and consultants, and did not incorporate the perspectives of patients or family members whose input is often required in decisions about end of life treatment. To do this would require a prospective study in real time, and our results can guide future researchers in this endeavour. Our cohort excluded patients at the end of life who were discharged to alternative care models such as hospice or palliative care. In doing so we implicitly assume that NBT was not provided to these patients; this is an untested assumption that should be explored in future studies. Furthermore, while we used a consensus definition of NBT, the definition of NBT in itself is subjective and value-laden and its interpretation may differ between individuals. ${ }^{7}$ Further limitations associated with the statistical methods we applied are included in online supplementary file 3 .

Future studies should focus on identifying how NBT may be better recognised in practice, and developing interventions to prevent it from occurring. Saini et al have described the complex interplay of social, economic, political and psychological factors that contribute to the broader issue of treatment overuse. ${ }^{37}$ Solutions are likely to require systemic change in the organisation of health systems and services, as well as individual level changes in the behaviours of medical professionals. Attention to patient preferences is central to this effort. ${ }^{38}$

We adopted an objective, data-based approach to estimate the factors associated with NBT at the end of life. There is a need for further research to confirm these findings and to explain the reasons behind them. Nonetheless, our results indicate the need for interventions to better manage conflicts in end of life care, both in medical teams and in families. The differences in the risk of NBT between hospitals suggests that successful interventions may also address institutional-level factors.

\section{Author affiliations}

${ }^{1}$ Australian Centre for Health Services Innovation, Institute of Health and Biomedical Innovation, School of Public Health and Social Work, Faculty of Health, Queensland University of Technology, Brisbane, Queensland, Australia

${ }^{2}$ School of Psychology, Faculty of Health and Behavioural Sciences, The University of Queensland, St Lucia, Queensland, Australia

${ }^{3}$ Faculty of Medicine, The University of Queensland, Brisbane, Queensland, Australia ${ }^{4}$ Royal Brisbane and Womens Hospital, Herston, Queensland, Australia

${ }^{5}$ Australian Centre for Health Law Research, Faculty of Law, Queensland University of Technology, Brisbane, Queensland, Australia

${ }^{6}$ Duke-NUS Medical School, Singapore, Singapore

Acknowledgements The authors would like to acknowledge Mary Anne Patton, Letitia Burridge and Gayle Salkield for their contributions to data acquisition.

Contributors All authors (HC, XJL, CG, SW, LC, LW, BW, MP, EC and NG) made substantial contributions to the conception or design of the work. SW and CG acquired the data. HC, XJL and NG analysed the data. All authors had access to and interpreted the data. $\mathrm{HC}$ drafted the manuscript and all authors critically revised it for intellectual content. All authors gave final approval and agree to be accountable for all aspects of the work.

Funding This research was funded by the Australian Research Council Linkage (project number LP121000096). The funder had no role in the study design; the collection, analysis, and interpretation of data; in the writing of the manuscript; and in the decision to submit the article for publication. All researchers involved in this work were independent from the funder. All authors had full access to all of the data (including statistical reports and tables) in the study and can take responsibility for the integrity and accuracy of the data.

Competing interests None declared.

Patient consent for publication Not required.

Ethics approval Multisite ethics approval for all three hospitals from the Metro South Hospital and Health Service Human Research Ethics Committee, approval number HREC/13/QPAH/651. Also obtained administrative approval from The University of Queensland Human Research Ethics Committee, approval number 2014000909 and Queensland University of Technology University Human Research Ethics Committee, approval number 1400000541. Public Health Act approval from the Office of the Director General at the Queensland Department of Health (allows access of confidential information, given the patients were deceased and so could not consent), approval number RD005108.

Provenance and peer review Not commissioned; externally peer reviewed.

Data availability statement Data are available upon reasonable request.

Open access This is an open access article distributed in accordance with the Creative Commons Attribution Non Commercial (CC BY-NC 4.0) license, which permits others to distribute, remix, adapt, build upon this work non-commercially, and license their derivative works on different terms, provided the original work is properly cited, appropriate credit is given, any changes made indicated, and the use is non-commercial. See: http://creativecommons.org/licenses/by-nc/4.0/.

\section{ORCID iDs}

Hannah Elizabeth Carter http://orcid.org/0000-0002-0046-4126

Xing Ju Lee http://orcid.org/0000-0002-8803-2810

Leonie Callaway https://orcid.org/0000-0002-0137-9935

Lindy Willmott https://orcid.org/0000-0002-9750-287X

Ben White https://orcid.org/0000-0003-3365-939X

Malcolm Parker https://orcid.org/0000-0002-8132-0115

Eliana Close https://orcid.org/0000-0002-7359-3375

Nicholas Graves http://orcid.org/0000-0002-5559-3267

\section{REFERENCES}

1 Kasman DL. When is medical treatment futile? A guide for students, residents, and physicians. J Gen Intern Med 2004;19:1053-6.

2 Carter HE, Winch S, Barnett AG, et al. Incidence, duration and cost of futile treatment in end-of-life hospital admissions to three Australian public-sector tertiary hospitals: a retrospective multicentre cohort study. BMJ Open 2017;7:e017661.

3 Huynh TN, Kleerup EC, Raj PP, et al. The opportunity cost of futile treatment in the ICU*. Crit Care Med 2014;42:1977-82. 
4 Huynh TN, Kleerup EC, Wiley JF, et al. The frequency and cost of treatment perceived to be futile in critical care. JAMA Intern Med 2013;173:1887-94.

5 Mobley MJ, Rady MY, Verheijde JL, et al. The relationship between moral distress and perception of futile care in the critical care unit. Intensive Crit Care Nurs 2007;23:256-63.

6 Schwarzkopf D, Rüddel H, Thomas-Rüddel DO, et al. Perceived nonbeneficial treatment of patients, burnout, and intention to leave the job among ICU nurses and junior and senior physicians. Crit Care Med 2017;45:e265-73.

7 White B, Willmott L, Close E, et al. What does "futility" mean? An empirical study of doctors' perceptions. Med J Aust 2016;204.

8 Bosslet GT, Pope TM, Rubenfeld GD, et al. An official ATS/AACN/ ACCP/ESICM/SCCM policy statement: responding to requests for potentially inappropriate treatments in intensive care units. $A m \mathrm{~J}$ Respir Crit Care Med 2015;191:1318-30.

9 Berwick DM. Avoiding overuse-the next quality frontier. The Lancet 2017;390:102-4.

10 Cardona-Morrell M, Kim J, Turner RM, et al. Non-Beneficial treatments in hospital at the end of life: a systematic review on extent of the problem. Int J Qual Health Care 2016;28:456-69.

11 Willmott L, White B, Gallois C, et al. Reasons doctors provide futile treatment at the end of life: a qualitative study. J Med Ethics 2016;42:496-503.

12 Sibbald R, Downar J, Hawryluck L. Perceptions of "futile care" among caregivers in intensive care units. CMAJ 2007;177:1201-8.

13 Downar J, You JJ, Bagshaw SM, et al. Nonbeneficial treatment Canada: definitions, causes, and potential solutions from the perspective of healthcare practitioners ${ }^{*}$. Crit Care Med 2015;43:270-81.

14 Oerlemans AJM, van Sluisveld N, van Leeuwen ESJ, et al. Ethica problems in intensive care unit admission and discharge decisions: a qualitative study among physicians and nurses in the Netherlands. BMC Med Ethics 2015;16:9.

15 Piers RD, Azoulay E, Ricou B, et al. Inappropriate care in European ICUs: confronting views from nurses and junior and senior physicians. Chest 2014;146:267-75.

16 Anstey MH, Adams JL, McGlynn EA. Perceptions of the appropriateness of care in California adult intensive care units. Crit Care 2015;19.

17 Giannini A, Consonni D. Physicians' perceptions and attitudes regarding inappropriate admissions and resource allocation in the intensive care setting. Br J Anaesth 2006;96:57-62.

18 Palda VA, Bowman KW, McLean RF, et al. "Futile" care: Do we provide it? Why? A semistructured, Canada-wide survey of intensive care unit doctors and nurses. J Crit Care 2005;20:207-13.

19 Marck $\mathrm{CH}$, Weil J, Lane $\mathrm{H}$, et al. Care of the dying cancer patient in the emergency department: findings from a national survey of Australian emergency department clinicians. Intern Med $J$ 2014;44:362-8
20 Piers RD, Azoulay E, Ricou B, et al. Perceptions of appropriateness of care among European and Israeli intensive care unit nurses and physicians. JAMA 2011;306:2694-703.

21 Taylor DR, Lightbody CJ. Futility and appropriateness: challenging words, important concepts. Postgrad Med J 2018;94:238-43.

22 von Elm E, Altman DG, Egger M, et al. The strengthening the reporting of observational studies in epidemiology (STROBE) statement: guidelines for reporting observational studies. PLoS Med 2007;4:10.

23 World Health Organisation. International statistical classification of diseases and related health problems. - 10th revision. 5th edn. Geneva, 2016

24 Chatterjee S, Hadi A. In: Sons JW, ed. Regression analysis by example. 5 edn, 2012.

25 Schwarz G. Estimating the dimension of a model. The Annals of Statistics 1978;6:461-4.

26 Calcagno V, Mazancourt Cde. glmulti: An $R$ Package for Easy Automated Model Selection with (Generalized) Linear Models. J Stat Softw 2010;34:1-29.

27 Burnham KP, Anderson DR. Model selection and multimodel inference: a practical information-theoretic approach. Springer Science \& Business Media, 2003.

28 Harrell FE. Regression modeling strategies as implemented in $R$ package 'rms' version (Section 4.3), 2014.

29 Harrell F. Variable selection, multivariable modeling strategies. regression modeling strategies. 2nd edn. New York: Springer, 2015: 67-72.

30 Winter L, Parks SM. Family discord and proxy decision makers' endof-life treatment decisions. J Palliat Med 2008;11:1109-14.

31 NSW Department of Health. Conflict resolution in end of life settings (CRELS): final CRELS Working Group report including consultation summary. Canberra: NSW Department of Health, 2010.

32 Way D, Tracy SJ. Conceptualizing Compassion as Recognizing, Relating and (Re)acting: A Qualitative Study of Compassionate Communication at Hospice. Commun Monogr 2012;79:292-315.

33 Betcher DK. Elephant in the room project: improving caring efficacy through effective and compassionate communication with palliative care patients. Medsurg Nursing 2010;19.

34 Bosslet GT, Kesecioglu J, White DB. How should clinicians respond to requests for potentially inappropriate treatment? Intensive Care Med 2016;42:422-5.

35 Cruz VMda, Camalionte L, Caruso P. Factors associated with futile end-of-life intensive care in a cancer Hospital. Am J Hosp Palliat Care 2015;32:329-34.

36 Neville TH, Tarn DM, Yamamoto M, et al. Understanding factors contributing to inappropriate critical care: a mixed-methods analysis of medical record documentation. J Palliat Med 2017;20:1260-6.

37 Saini V, Garcia-Armesto S, Klemperer D, et al. Drivers of poor medical care. The Lancet 2017;390:178-90.

38 Saini V, Brownlee S, Elshaug AG, et al. Addressing overuse and underuse around the world. The Lancet 2017;390:105-7. 